\title{
THE TREATMENT OF THE OFFENDER
}

\author{
By Homer Folks,
}

Secretary, New York State Charities Aid Association; President, New York State Probation Commission.

The student of social economy fifty years hence, looking back on our existing social agencies and practices, will find nothing more difficult to understand, and to harmonize with the possession of intelligent purposes on our part, than our treatment of the offender. He will not criticise us because our policy in dealing with the offender was too lenient, nor because it was too severe; not because our treatment of the offender was too largely institutional, nor too little institutional; but because we had no policy. He will criticise us because we vacillated between accepting, on the one hand, the findings and teachings of scientific study and research in social conditions and criminology and adhering on the other to the medieval idea of punishment.

In thus generally condemning our treatment of offenders, I am not unmindful of progress made. I remember that we have an Elmira Reformatory, and that there are similar institutions in other states; that improvements have taken place in equipment and discipline in some prisons; that the indeterminate sentence has been adopted, coupled more and more with some form of parole oversight; and that juvenile courts and the suspension of sentence with probationary oversight for both children and adults have been quite generally authorized.

The fact that notwithstanding these improvements, our system of dealing with offenders must as a whole be pronounced a failure, is, in my judgment, due, among other reasons, largely to four things, viz.:

I. The persistence of wrong notions as to the purpose of punishment.

2. The failure to provide adequate machinery for making the suspended sentence with probationary oversight, and the indeterminate sentence with oversight during parole, really effective.

3. The failure to collect adequate and comprehensive informa-

(20) 
tion as to the actual operations of our correctional institutions and reform systems, by means of which we could elaborate a broader, more consistent and more effective program, and defend it against all comers.

4. The traditionalism of most of our magistrates and judges, and the attitude encouraged by many lawyers and some others, of not subjecting courts to criticism as we do other institutions.

Time permits but a brief amplification of these four points:

I. The latest reactionary statement to attract general notice is an address before the Association of District Attorneys of the State of New York, March 17, I9I0, by Charles C. Nott, Jr., a leading member of the staff of the District Attorney of New York City. Mr. Nott probably expresses in considerable degree the sentiments of the staff of that office, and to some extent of the present and past efficient incumbents of the office of District Attorney, Mr. Whitman and Mr. Jerome. Mr. Nott begins his paper with the following assertion:

"It seems safe to assert that for many years it has been held by all intelligent people interested in penology, that the purpose of imprisonment for crime is to safeguard the interests of the community by deterring others from the commission of crime."

While agreeing with some of the positions taken by Mr. Nott, I must distinctly take issue with this statement. The chief purpose of punishment in the mind of the average man, and, therefore, of the community as a whole, in my judgment, is to prevent the commission of further crime, not by other offenders, but by the particular offender in question. I appeal to general experience and instinctive feeling in regard to crimes committed in our neighborhoods or within the range of our personal knowledge-is not our first and most insistent feeling the desire to be protected from further crimes by this particular offender? It is for this reason that we instinctively wish to put him behind bars, and in an earlier age instinctively wished to take off his head. We may hope that incidentally others who may be wavering may also be deterred from wrongdoing, but experience seems to show that it is very uncertain as to whether the punishment of one offender does have much effect upon others.

Fortunately, the deterrent effect of punishment upon an offender 
is one which we can very accurately measure. We can, if we will, be fully informed as to the extent to which our actual dealings with convicted offenders do deter them from further crimes. We know their names, their places of abode. We can, if we will, identify them by a system which precludes doubt. We can make such identification of convicted offenders general, and we can, if we think it worth while, and, of course, it is supremely worth while, know beyond peradventure what proportion of convicted offenders who are treated in penal institutions subsequently repeat their offenses, and what proportion of those released on probationary oversight or suspended sentence again offend.

If, however, the chief object of punishment is to deter others from committing crime, we can never know to what extent that object is accomplished. It is doubtful whether our statistics in regard to crime will be such for a long time to come that we can form any accurate notion as to the actual amount of crime at one time as compared with another. Even if we achieved a reasonably accurate measurement of the volume of crime, its causes are too obscure and complicated to enable us to single out the effect at one period and at another of this particular factor, the deterrent effect of punishment on others. The impossibility of securing definite information is, in fact, probably one of the chief reasons for the persistence of the idea, in my judgment erroneous, which Mr. Nott makes the corner-stone of his paper.

II. The indeterminate sentence with parole oversight and the suspended sentence with probationary oversight are already too firmly established to be overturned by the reactionary attacks which will doubtless be made upon them from time to time. They are correct in principle; they have come to stay; and the area of their application will be extended rather than restricted. I am far, however, from saying that their present administration is satisfactory. It is, in my opinion, in most localities and in most courts highly unsatisfactory, and it is unsatisfactory principally because we have failed to provide the facilities by which we can secure effective supervision of persons so released. Specifically, we have utterly failed in most courts to provide anything like an adequate number of qualified probation officers, and we have failed still more lamentably to devise an adequate system for the direction of the work of probation officers. It is absolutely essential in probation work 
that the offender shall be kept under an actual, vital, effective oversight, and that, if such oversight shows that he is continuing in wrongdoing, the suspended sentence should be revoked and the proper sentence be imposed.

Mr. Nott criticises particularly the number of suspensions of sentence and questions the effectiveness of probationary oversight in the Court of General Sessions in the city of New York. The number of suspensions of sentences increased from 460 in 1904 to I 160 in 1908 , and 982 in 1909 . As to whether there is an undue number of defendants so dealt with; as to whether sentence has been suspended in wrong instances and by reason of ignorance of the facts or of improper motives, I have no data on which to base an opinion. I am perfectly clear, however, that, as Mr. Nott implies, the number of persons released in that court under suspension of sentence is such as to require for their effective oversight a large, well-organized staff of competent probation officers, devoting their entire time to the work, and properly superintended.

The judges of that court have not seen fit to ask the city authorities to provide salaries for any probation officers whatever. They rely upon voluntary assistants provided by private organizations. It is manifestly impossible for the representatives of these organizations, with the other duties imposed upon them, and in some instances with private occupations, to perform efficiently the amount of work placed upon them by the court. There is no chief probation officer to direct the work of these volunteers. The State Probation Committee informally but strongly urged the judges of this court more than a year ago to make an application to the city authorities for salaries for a staff of probation officers, and has offered to support a request for such an appropriation. It will doubtless be forthcoming, as it has been when requested by other courts.

Still more notably deficient in my judgment, both in method and facilities, is the oversight of persons released from penal and reformatory institutions on parole. To determine when an offender may properly be paroled is a matter requiring careful inquiry and great discretion. It should be determined with very full knowledge of the offender's conduct, both in the institution and before commitment. It is a highly individual matter. The machinery provided for a determination of the proper time to release a prisoner on 
parole, is woefully inadequate. The presumption that all offenders who have behaved tolerably well in prison are entitled to parole at the expiration of the minimum period of imprisonment is absolutely inconsistent with the idea of the indeterminate sentence. Yet this appears to be an accepted practice in New York, and on this basis a member of the State Parole Board justified the release, at the expiration of the minimum term, of a most notorious offender against the election laws. And when the offender is actually paroled, with an indeterminate sentence still hanging over his head, what sort of a method have we worked out for keeping informed as to his conduct? Who selects the parole officers; who directs them from day to day; who works out the standards on which the question of the return of an offender to a penal institution is to be determined; who sees that these standards are impartially enforced? Our management of penal and reformatory institutions has improved much faster than our management of the processes of getting persons into and out of such institutions?

To the question, "Is Christianity a failure?" some one objected that it had never yet been tried. Should any one remark that probation and parole are failures, I am inclined to reply that they have never yet been thoroughly and effectively tried. There is nothing flabby, weak, sentimental or ineffectual in the theory or in the proper administration of probation or parole. The supervision which they pre-suppose may be even more objectionable to an offender than actual imprisonment. The crying need, however, is for methods, facilities, agencies, officers, which will permit the theory of probation and parole to be put into actual practice.

III. The lack of comprehensive, trustworthy and instructive statistics in regard to offenders and their treatment, is notorious. It must be referred to because it is one of the important elements in the situation. By reason of it we are still asking, after thirty-two years of Elmira, whether reformatories reform. We are still in the dark to an unpardonable extent as to whether persons released under suspended sentence and under probation repeat their offenses. We are still in the dark as to the extent to which prisoners released from penal institutions under indeterminate sentence again offend, either during the term of parole or subsequently. The curious thing about it is that not only do we fail to collect such information, but curiously enough we apparently fail to realize that without it 
we cannot develop an intelligent and consistent policy in dealing with offenders. It is for this that we will be criticised most sharply fifty years hence. Not even to know that we are groping in the darkness is unpardonable.

IV. Lastly, but in my judgment of exceeding importance, is the attitude of mind entertained and inculcated by many in regard to the courts generally. We are told that we must not criticise the courts; that they are in some way different from other human institutions; that they must be accepted, supported, obeyed, revered, but not criticised. This tends to maintain an attitude of superstition; it tends to dry rot in the court; it encourages political favoritism and downright corruption; it perpetuates hoary abuses in the business and administrative sides of the court's work. We shall not reach a consistent, defensible policy of dealing with offenders until we recognize generally that judges are very human; that to err is human, but that erring calls for criticism and correction. Lots of sunlight, fresh air, and ventilation will tend to prevent abuses in the courts, as well as to prevent tuberculosis.

If you have happened to call at the executive chamber in Albany, you may have noticed that at 12 o'clock and at 5 o'clock daily the representatives of the press are admitted, and meet the governor in person. In its superficial aspect this is a meeting between a very distinguished man and a few young men representing newspapers. In reality it is the highest executive official in the state giving twice daily an account of his stewardship to the people of the state. Similarly, every act of the legislature is daily under the searchlight of publicity. In some way our criminal courts, in my judgment, should be made subject to equally potent, constructive influences. We must know the facts; we must know them promptly; and we must be ready to express judgment upon them and to act upon them if need be. We must bear constantly in mind the human quality of the court. That which we deem judicial severity we must remember may be due in part to a too elaborate dinner on the part of the judge the night before. That which we deem striking confidence in the prisoner's good faith may be born of a favorable turn the day before in the properties in which the judge's savings are invested.

The fact that people know so little about the courts and that they have been taught to have an attitude of almost fetish-worship 
toward them, leaves them in a state of mind to readily go to the other extreme and unjustly and unreasonably condemn particular courts or particular judges as corrupt or hopelessly unenlightened.

An attitude of open-minded criticism toward the courts would, in my judgment, be a most helpful factor in the development of their work. The recent report of the Commission to Inquire Into the Courts of Inferior Criminal Jurisdiction in Cities of the First Class in the State of New York is an admirable example of impartial, wholesome criticism of court methods, procedure and results. It is unfortunate that it is the report of a temporary body. We should have some similar continuing organ of government by which at stated intervals the important facts in relation to criminal courts, especially of inferior jurisdiction, wotld be stated in such a way as to inform the public, and form the basis for remedial and constructive measures. The courts, as well as the penal institutions, should be studied, inspected and improved. The most important factor in this process is that of securing reasonably continuous, wellinformed, intelligent publicity, in place of the present long periods of obscurity, broken by brief intervals of often undeserved public condemnation. 